\title{
Compressive Strength and Interface Microstructure of PCBN Grains Brazed with High-Frequency Induction Heating Method
}

\author{
Ye-Jun Zhu ${ }^{1} \cdot$ Wen-Feng Ding ${ }^{1} \cdot$ Ze-Yu Zhao ${ }^{1} \cdot$ Yu-Can Fu ${ }^{1} \cdot$ Hong-Hua Su ${ }^{1}$
}

Received: 8 November 2016/Revised: 7 December 2016/Published online: 1 April 2017

(C) The Chinese Society for Metals and Springer-Verlag Berlin Heidelberg 2017

\begin{abstract}
In order to prepare monolayer brazed superabrasive wheels, the polycrystalline cubic boron nitride (PCBN) grains were brazed to AISI 1045 steel matrix with $\mathrm{Ag}-\mathrm{Cu}-\mathrm{Ti}$ filler alloy using the high-frequency induction heating technique. The compressive strengths of brazed grains were measured. Morphology, chemical composition and phase component of the brazing resultant around PCBN grain were also characterized. The results show that the maximum compressive strength of brazed grains is obtained in the case of brazing temperature of $965^{\circ} \mathrm{C}$, which does not decrease the original grain strength. Strong joining between $\mathrm{Ag}-\mathrm{Cu}-\mathrm{Ti}$ alloy and PCBN grains is dependent on the brazing resultants, such as $\mathrm{TiB}_{2}$, TiN and $\mathrm{AlTi}_{3}$, the formation mechanism of which is also discussed. Under the given experimental conditions, the optimum heating parameters were determined to be current magnitude of $24 \mathrm{~A}$ and scanning speed of $0.5 \mathrm{~mm} / \mathrm{s}$. Finally, the brazing-induced residual tensile stress, which has a great influence on the grain fracture behavior in grinding, was determined through finite element analysis.
\end{abstract}

\section{KEY WORDS: High-frequency induction brazing; PCBN grain; Compressive strength; Interface} microstructure; Residual stress

\section{Introduction}

Polycrystalline cubic boron nitride (PCBN) grains are newly developed super-hard material, which is synthesized by microcrystalline CBN particles and AlN binder [1]. Due to the unique microstructure, microcrystalline CBN particles in PCBN grains might fall out from the grain when they are blunt under a proper load in grinding, which overcomes cleavage and aeolotropies of the traditional monocrystalline CBN grains [2-4]. Ding et al. [5] have investigated the grain wear and fracture mechanism of

Available online at http://link.springer.com/journal/40195.

Wen-Feng Ding

dingwf2000@vip.163.com

1 College of Mechanical and Electrical Engineering, Nanjing University of Aeronautics and Astronautics, Nanjing 210016, China
PCBN abrasive tools during constant-force grinding of Ti$6 \mathrm{Al}-4 \mathrm{~V}$ alloy, and they have found that the tools with the PCBN abrasive grains could maintain the sharp cutting edges by the fracture of microcrystalline CBN particles. At the same time, Ichida et al. [6, 7] compared the grinding behaviors of the PCBN grains and the monocrystalline CBN grains, and they pointed out that the PCBN abrasive wheel had a lower wheel wear rate and longer wheel life. On account of the potential advantages in grinding, preparation and application of PCBN superabrasive wheels is one of the most important research topics in the present grinding community.

Compared with the monolayer electroplated abrasive wheels applied widely, the monolayer brazed abrasive wheels could escape the grains pullout due to the chemical reaction happening across the interface between the grains and bonding material [8-12]. Therefore, it is essential to develop and investigate the monolayer brazed PCBN abrasive wheels. Generally, in these days, brazing 
technology could be divided into three types based on the thermal sources: the laser brazing technique, vacuum resistance furnace brazing technique and high-frequency induction brazing technique, respectively [13]. However, it is usually rather difficult to control effectively the quality of monolayer abrasive wheels when using laser brazing technique. As for the vacuum resistance furnace brazing technique, the furnace chamber size and wheel matrix deformation usually limit the abrasive wheel dimension $[9,14,15]$. Furthermore, the dimension accuracy of abrasive wheel is always affected greatly because the whole abrasive tool has to be heated in the vacuum resistance furnace. On the contrary, the high-frequency induction brazing technology has some great advantages, such as rapid heating rate and locally heating, which could provide a good prospect to prepare the abrasive wheels with large diameter (i.e., $400 \mathrm{~mm}$ ) and high accuracy in dimension [16-19].

In recent years, the high-frequency induction brazing technique has gained importance to join various covalentbonded materials and metallic materials, some critical issues of which were also researched. For example, Tong et al. [20] investigated the thermal distribution within the grinding wheel matrix during the ultrahigh-frequency induction brazing process by finite element simulation. Ma et al. [21, 22] conducted a brazing experiment of the diamond grains with high-frequency induction brazing technique; they reported that the metallurgical bonding occurred not only at the interface of diamond grits and brazing alloy but also at the interface of brazing alloy and steel substrate of tools. In addition, Li et al. [23] indicated that the brazed CBN wheel produced by high-frequency induction brazing technique shows a good bonding strength during high-speed grinding of Inconel 718 superalloy. However, as the potential superabrasive grains, there is little information on preparation of monolayer brazed PCBN wheels based on high-frequency induction heating technology. Therefore, it is necessary to investigate mechanical strength and interfacial behavior of PCBN grains during the high-frequency induction brazing process.

In this article, the brazing experiments of PCBN grains and AISI 1045 steel matrix with $\mathrm{Ag}-\mathrm{Cu}-\mathrm{Ti}$ alloy as filler material have been carried out using the high-frequency induction heating technique. The compressive strength and interface microstructure of brazed PCBN grains are conducted; furthermore, the corresponding mechanism is also discussed deeply. Accordingly, some key heating parameters, such as current magnitude and scanning speed, are optimized for high-frequency induction brazing of PCBN grains. Finally, an analysis of the brazing-induced residual tensile stress within the PCBN grains was conducted.

\section{Experimental Materials and Procedure}

The commercial PCBN grains with an average particle size of $375 \mu \mathrm{m}$ were adopted (exhibited in Fig. 1). AISI 1045 steel was chosen as the tool matrix $(300 \mathrm{~mm} \times$ $20 \mathrm{~mm} \times 100 \mathrm{~mm})$. PCBN grains and steel matrix were joined using $\left(\mathrm{Ag}_{72} \mathrm{Cu}_{28}\right)_{95} \mathrm{Ti}_{5}$ (wt\%) alloy as the filler material. Before brazing, the PCBN grains and steel matrix were firstly ultrasonically cleaned to remove the impurities. Then, PCBN grains and $\mathrm{Ag}-\mathrm{Cu}-\mathrm{Ti}$ alloy powder were sprayed uniformly over the steel matrix surface. The specimens (Sample No. 2-7 in Table 1) were brazed by using a developed auto-control induction heating system under high pure argon gas protection, with different current magnitudes and linear feeding speeds of induction coil, as schematically displayed in Fig. 2. In order to avoid the contact between the inductor and the grain and maintain the brazing efficiency, the brazing gap was selected as $2 \mathrm{~mm}$. The other brazing parameters, such as current magnitude and scanning speed, are listed in Table 1. The brazing temperature at Point A (midpoint of the matrix edge on top surface, shown in Fig. 2) was measured with $K$-type thermocouple. The stable digital potential difference signal was collected after the filtering and acquisition of the original signal.

Because strong joining between $\mathrm{Ag}-\mathrm{Cu}-\mathrm{Ti}$ alloy and AISI 1045 steel matrix is easily generated, the current work would pay a special attention on the joining interface between PCBN grains and $\mathrm{Ag}-\mathrm{Cu}-\mathrm{Ti}$ filler material, which was firstly characterized by scanning electron microscopy (SEM, Hitch S3400). Subsequently, the 10\% (mass fraction) dilute $\mathrm{HNO}_{3}$ solution was utilized as the electrolyte to separate the PCBN grains from the brazed samples; afterward, the grains were put in aqua regia for corrosion up to $72 \mathrm{~h}$, aiming to wipe off the residual filler on the grain surface. The static strength measuring equipment ZMC-II produced by Zhengzhou Research Institute for Abrasive and Grinding, China was applied to measure the static compressive strength of the brazed grains. The loading rate applied was $0.5 \mathrm{~mm} / \mathrm{min}$ with the measuring range from 1 to $100 \mathrm{~N}$, and the force error of $\pm 1 \%$. Particularly, the static strength of 40 PCBN grains, as one group for each brazing parameter, was measured. Moreover, totally three groups of the grains were measured for each brazing parameter. The arithmetic mean value of maximum compressive load $F(\mathrm{~N})$ was calculated. According to the literature [7, 24-26], the static compressive strength $\sigma(\mathrm{MPa})$ of the grains could be determined as follows:

$\sigma=1.37 F / d_{\mathrm{s}}^{2}$,

where $d_{\mathrm{s}}$ is diameter of the PCBN grain $(\mathrm{mm})$.

In addition, the morphology and chemical composition of the brazing resultants around PCBN grain were examined by SEM and energy dispersive X-ray spectroscopy (EDS, Bruker 

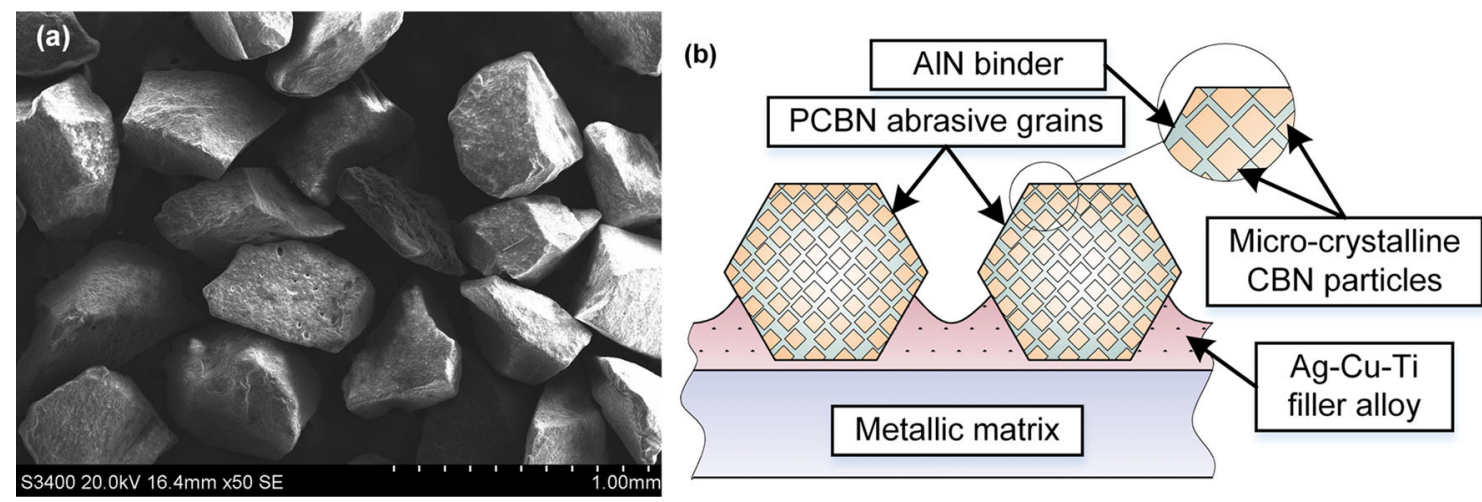

Fig. 1 Schematic diagram of PCBN grains: a micrograph of original PCBN grains, $\mathbf{b}$ schematic diagram of brazed PCBN grains

Table 1 Measured brazing temperatures of PCBN grains under different heating parameters

\begin{tabular}{llll}
\hline Sample No. & Current magnitude, $I(\mathrm{~A})$ & Scanning speed, $v(\mathrm{~mm} / \mathrm{s})$ & Highest heating temperature, $T\left({ }^{\circ} \mathrm{C}\right)$ \\
\hline 1 & Original grains & & 823 \\
2 & 20 & 0.5 & 900 \\
3 & 22 & 0.5 & 852 \\
4 & 24 & 1 & 965 \\
5 & 24 & 0.5 & 1087 \\
6 & 24 & 0.25 & 1030 \\
7 & 26 & 0.5 & \\
\hline
\end{tabular}
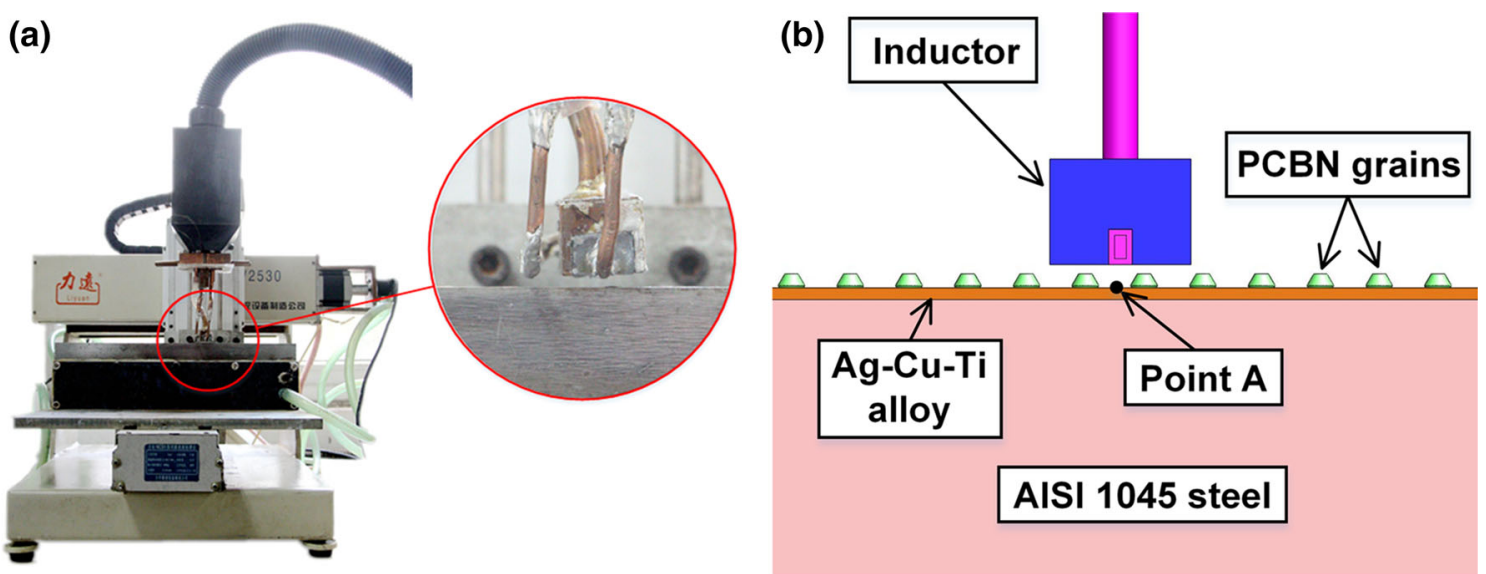

Fig. 2 Schematic representation of induction brazing of PCBN grains: a brazing equipment, b schematic diagram

XFlash Detector 5010). Phase components were identified by $\mathrm{X}$-ray diffraction (XRD, D/max 2500/PC).

\section{Results and Discussion}

\subsection{Effect of Heating Parameters on Temperature Variation and PCBN Grains Strength}

Figure $3 \mathrm{a}, \mathrm{b}$ provides the variation curve of heating temperature at Point A (see Fig. 2b) in the current high- frequency induction brazing system. The heating temperature rose higher when the coil was placed closer to Point A and fell off after Point A was passed. The induction heating parameters, combined with the corresponding maximum heating temperature, are listed in Table 1. Under the condition of constant scanning speed (such as $v=0.5 \mathrm{~mm} / \mathrm{s}$ ), the temperature went up when the current magnitude increased. Meanwhile, the compressive strength of brazed PCBN grains increased initially and then decreased with the climbing brazing temperature, as displayed in Fig. 4a. The grains compressive strength reached 

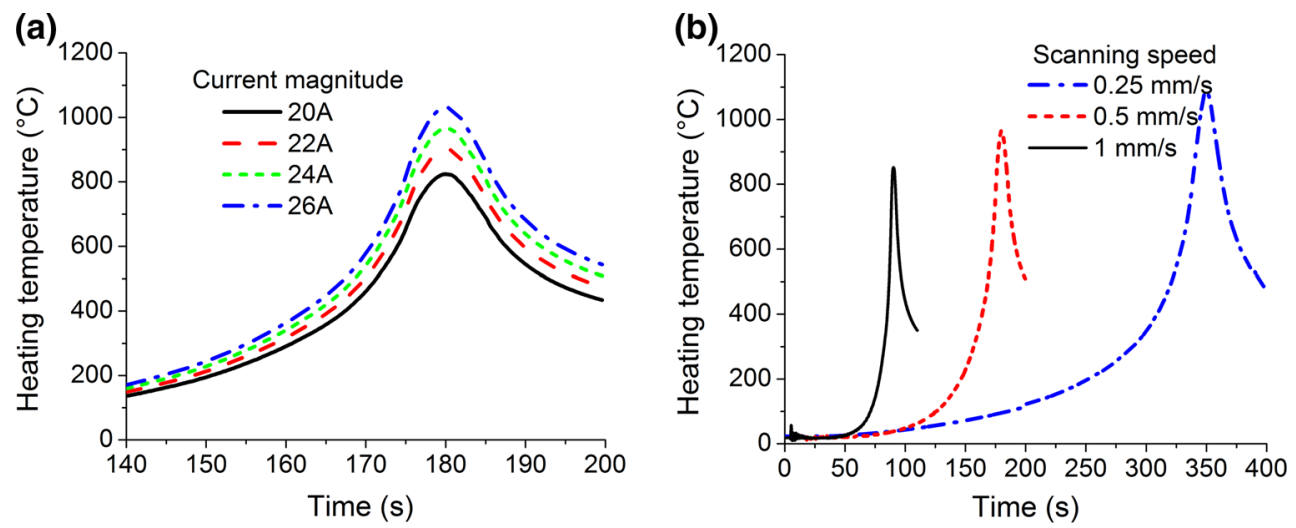

Fig. 3 Heating temperature curves obtained at Point $A$ versus heating parameters: a current magnitudes; $\mathbf{b}$ scanning speeds

the maximum value, such as 437.1 $\mathrm{MPa}$ in the case of the brazing temperature of $965^{\circ} \mathrm{C}(I=24 \mathrm{~A})$. At this time, the compressive strength of the brazed grain is $11.3 \%$ higher than that of the original grains. Furthermore, when the current magnitude kept constant $(I=24 \mathrm{~A})$ and the scanning speed double reduced, a similar tendency of brazing temperature and compressive strength was obtained, as demonstrated in Figs. $3 \mathrm{~b}$ and $4 \mathrm{~b}$.

On the other hand, the PCBN grain is a typical brittle material. Therefore, the grain strength distribution could be investigated by the Weibull weak link theory [3, 24]. Figure 5 displays the influence of the brazing parameters (e.g., current magnitude and scanning speed) on the Weibull strength distribution of the PCBN grain. The parameter $P$ in Fig. 5 refers to the cumulative frequency of the compressive strength $\sigma$. The Weibull modulus $M$ of the grains is listed. As illustrated in Fig. 5a, when the current magnitude was $26 \mathrm{~A}$, the modulus $M$ of the grains reached the maximum, and the modulus $M$ got the minimum when the current magnitude was $24 \mathrm{~A}$. In addition, the effect of scanning speed on the modulus $M$ is displayed in Fig. $5 \mathrm{~b}$. The modulus $M$ with the original grains got the maximum, when the scanning speed was $0.5 \mathrm{~mm} / \mathrm{s}$, the modulus $M$ got the minimum. According to the literature [7], the larger the
Weibull modulus $M$ is, the more stable the grain strength distribution is. Therefore, it is known that the strongest fluctuation of grain strength distribution is obtained in the case of the current magnitude of $24 \mathrm{~A}$ and the scanning speed of $0.5 \mathrm{~mm} / \mathrm{s}$.

During the induction brazing process at elevated temperatures, the thermal damage of brazed PCBN grains may be produced, which gives rise to a reduction in grain compressive strength. However, in the current work, this phenomenon did not happen for the PCBN grains when the brazing temperature was below $965^{\circ} \mathrm{C}$. The reason is that the microscopic pits and defects on the original grain surface have been filled up by the brazing resultants, which can reinforce PCBN grains to a certain extent. It is noted that, when the brazing temperature was further increased to above $965^{\circ} \mathrm{C}$, the compressive strength of brazed PCBN grains decreased because of the aggravated thermal damage. Accordingly, it is inferred that the grains brazed at the current magnitude of $24 \mathrm{~A}$ and the scanning speed of $0.5 \mathrm{~mm} / \mathrm{s}$ (that is, sample No. 5) can achieve the maximum compressive strength, which is therefore determined as the optimum heating parameters under the given experimental conditions. However, it is necessary to point out that the optimum heating parameters listed above happen to be the strongest fluctuation parameters
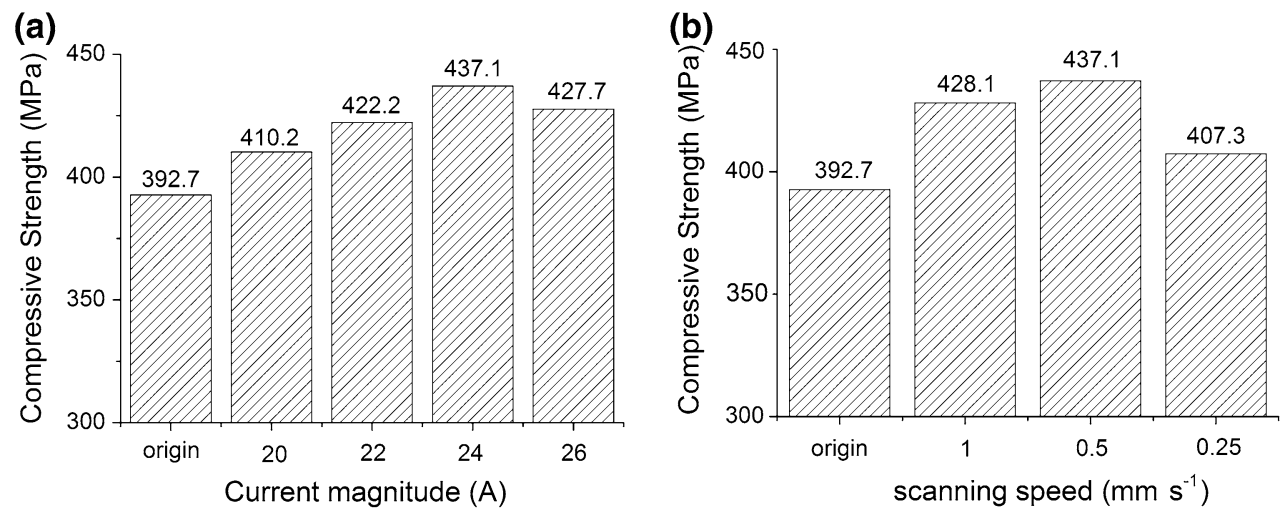

Fig. 4 Compressive strength of brazed PCBN grains versus heating parameters: a current magnitudes; b scanning speeds 

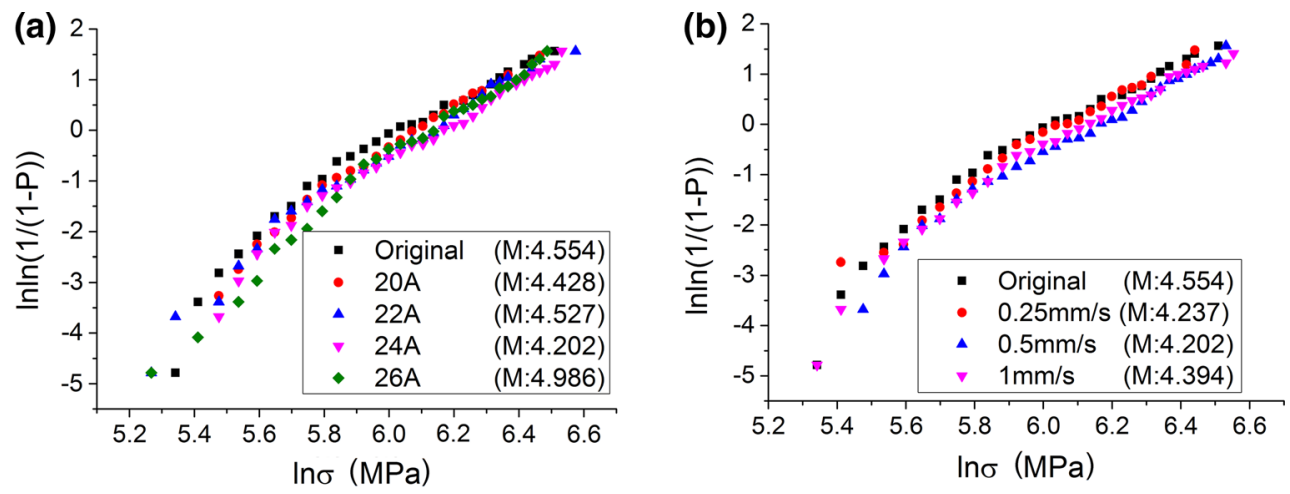

Fig. 5 Weibull distribution of grain compressive strength versus heating parameters: a current magnitudes; b scanning speeds

according to the Weibull strength distribution. The method to make the strength distribution stable will be investigated in the further research.

\subsection{Microstructure Characterization of Joining Interface}

The SEM micrograph coupled with EDS linear analysis results of joining interface of the brazed sample No. 5 is shown in Fig. 6. Obviously, good wetting behavior of molten $\mathrm{Ag}-\mathrm{Cu}-\mathrm{Ti}$ alloy occurred on the PCBN grain. The joining interface is well bonded, and there are no voids or cracks. The EDS element linear distributions of some important elements across the joining interface are displayed in Fig. 6c. A black region (Fig. 6b) with a thickness of about $3 \mu \mathrm{m}$ exists at the junction of PCBN grain and $\mathrm{Ag}-\mathrm{Cu}-\mathrm{Ti}$ filler alloy (depicted as $\mathrm{X}$ ). This region is enriched in $\mathrm{Ti}$, and the contents of $\mathrm{B}$ and $\mathrm{N}$ also show a gradient variation. The atomic diffusion across the interface implies the possibility of chemical reaction among the related elements, such as $\mathrm{Ti}, \mathrm{Al}, \mathrm{B}$ and $\mathrm{N}$ [27].

\subsection{Brazing Resultants Morphology of PCBN Grains}

Figure 7 shows the SEM images of original PCBN grain and resultants of the different brazed grains. Figure $7 \mathrm{~b}-\mathrm{d}$ corresponds to the brazed grains samples No. 4, No. 5 and No. 6, respectively. When the scanning speed slowed down in the present induction brazing, the reaction time was extended and the brazing temperature was increased, which therefore resulted in formation of adequate brazing resultants. For example, when the scanning speed was $1 \mathrm{~mm} / \mathrm{s}$, some irregular granular compounds were generated and distributed on the brazed grain surface (Fig. 7b). However, when the scanning speed was decreased to $0.5 \mathrm{~mm} / \mathrm{s}$, the granular compounds became larger, and some needleshaped resultants appeared on the grain surface (Fig. 7c). When the scanning speed was further decreased to $0.25 \mathrm{~mm} / \mathrm{s}$, some needle-shaped resultants turned into prismatic shape, closely arranged on the grain surface (Fig. 7d).

\subsection{Chemical Composition and Formation Mechanism of Brazing Resultant Layer}

The element distribution at different positions of the resultants is illustrated in Table 2. Figure 8 displays the XRD pattern of the brazing resultants of sample No. 5 . Obviously, in addition to the inherent BN phase and AlN phase in the PCBN grain, $\mathrm{TiN}, \mathrm{TiB}_{2}$ and $\mathrm{TiAl}_{3}$ were also detected at the brazed grain surface, which indicated that the chemical reaction took place in the induction brazing process. Moreover, the crystalline morphology of TiN
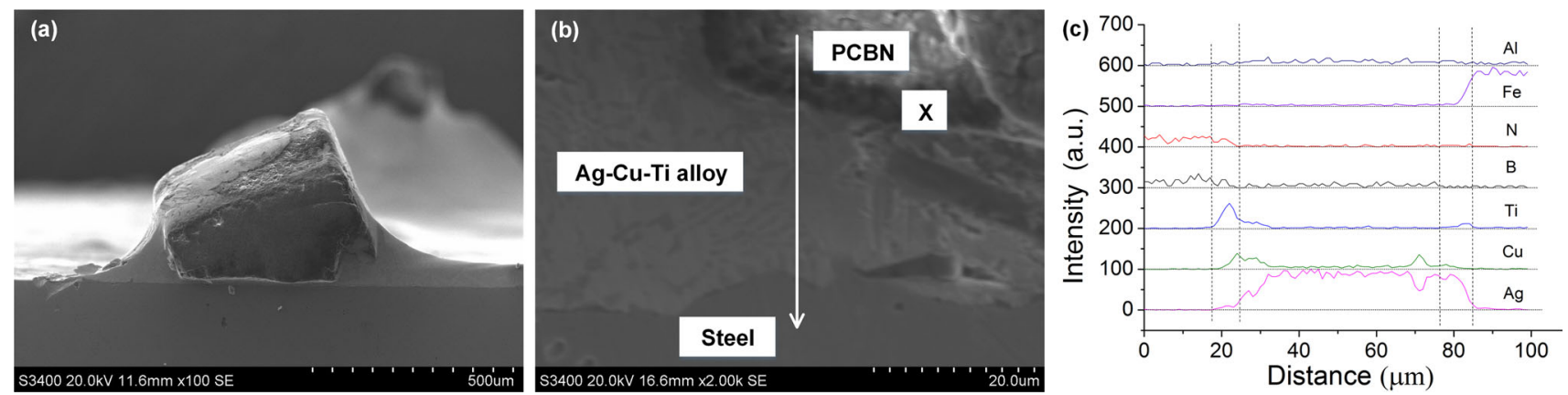

Fig. 6 Interfacial microstructure of brazed PCBN grains: a whole morphology, b joining interface, $\mathbf{c}$ element distribution curves 

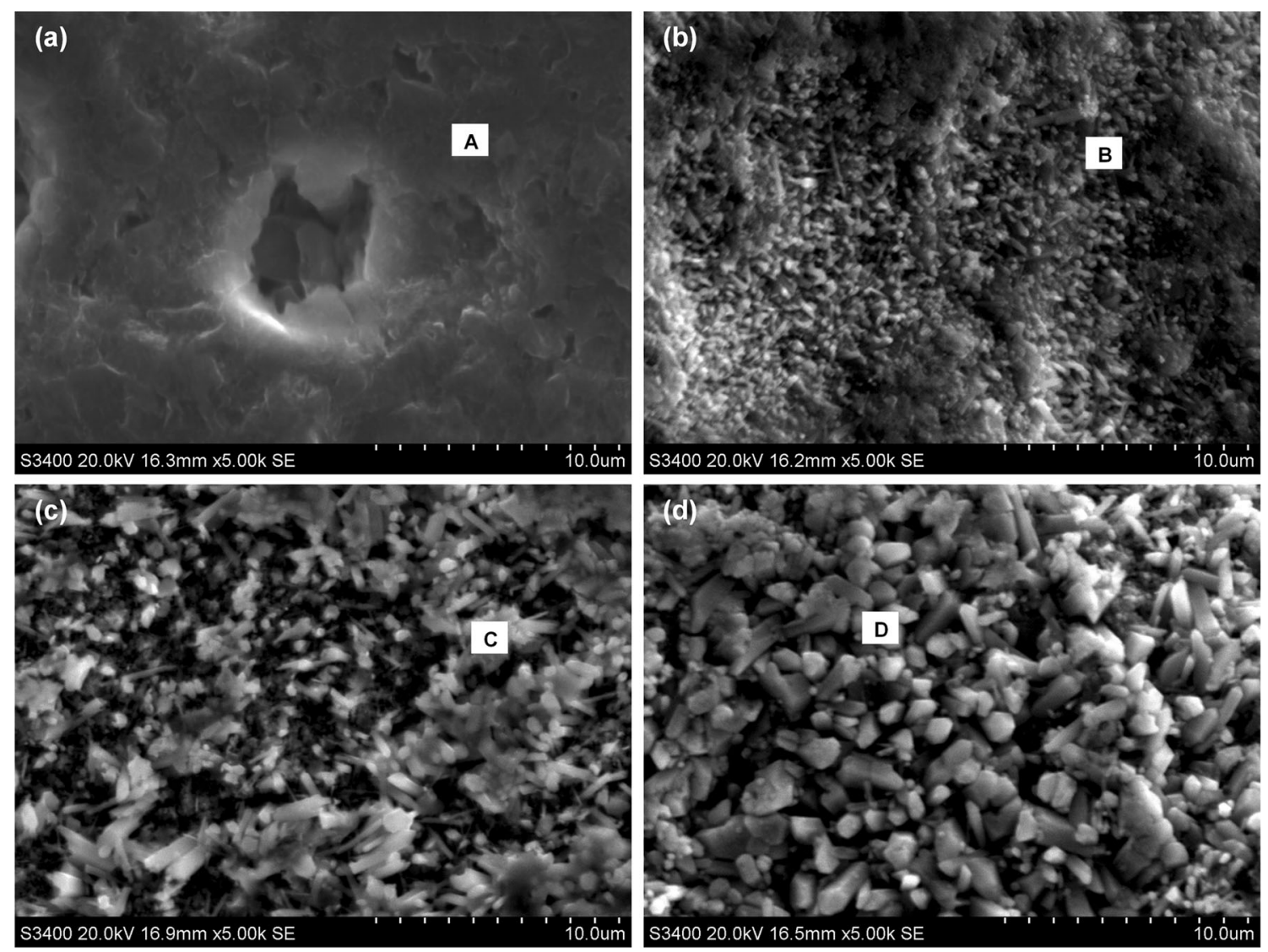

Fig. 7 Brazing resultant morphologies: a original grains, b Sample No. 4, c Sample No. 5, d Sample No. 6

generally presents irregular granules in shape [28], $\mathrm{TiB}_{2}$ is the most stable compound among B-Ti systems, showing a rod or whisker in shape [29]. Additionally, when the brazing temperature dropped below $900{ }^{\circ} \mathrm{C}$, the newly generated $\mathrm{TiAl}_{3}$ was elongated and became flaky-like in shape ultimately [30]. Based on the above analysis and the element distribution in Table 2, it can be proposed that the granular compound (denoted as $B$ in Fig. $7 \mathrm{~b}$ ) is TiN; the elongated and flaky shape compound (denoted as $C$ in Fig. 7c) is $\mathrm{TiAl}_{3}$; and the prismatic compound (denoted as $D$ in Fig. 7d) is $\mathrm{TiB}_{2}$.

During the induction brazing process, the granular TiN initially emerged on the PCBN grain surface. After the TiN was formed, $\mathrm{Al}$ and $\mathrm{B}$ atoms would not accumulate near

Table 2 EDS analysis results at different detection positions

\begin{tabular}{llllr}
\hline Detection positions & \multicolumn{4}{l}{ Chemical composition (at.\%) } \\
\cline { 2 - 5 } & $\mathrm{Ti}$ & $\mathrm{B}$ & $\mathrm{N}$ & \multicolumn{1}{c}{$\mathrm{Al}$} \\
\hline $\mathrm{A}$ & 0 & 35.1 & 19.2 & 45.84 \\
$\mathrm{~B}$ & 40.22 & 23.1 & 28.3 & 8.33 \\
$\mathrm{C}$ & 35.45 & 25.7 & 17.4 & 21.53 \\
$\mathrm{D}$ & 38.62 & 29.3 & 20.1 & 12.06 \\
\hline
\end{tabular}

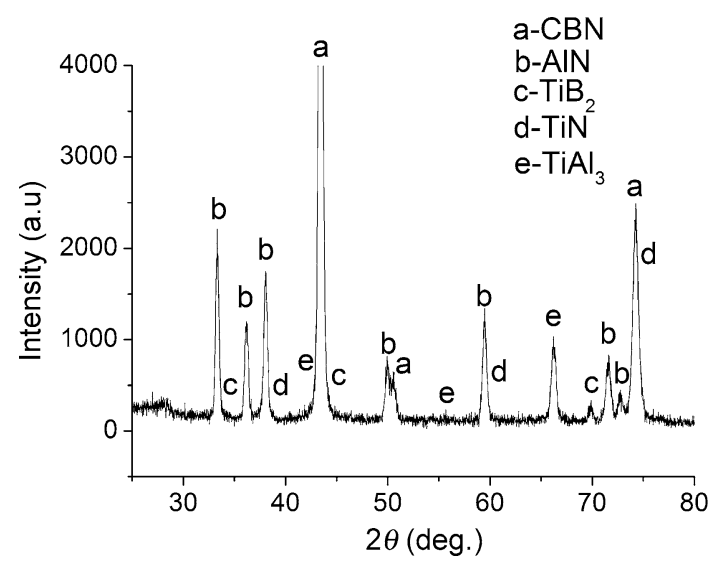

Fig. 8 XRD spectra of brazed grains of Sample No. 5

the new TiN layer owing to the effect of electromagnetic stirring; instead, they would react with Ti atoms to produce $\mathrm{TiAl}_{3}$ and $\mathrm{TiB}_{2}$ by penetrating the TiN layer. The chemical formulas of brazing reaction are as follows:

$3 \mathrm{Ti}+2 \mathrm{BN}=\mathrm{TiB}_{2}+2 \mathrm{TiN}$,

$4 \mathrm{Ti}+3 \mathrm{AlN}=\mathrm{TiAl}_{3}+3 \mathrm{TiN}$.

As for the above chemical reactions, both the Gibbs free energy values are negative in the current induction brazing 


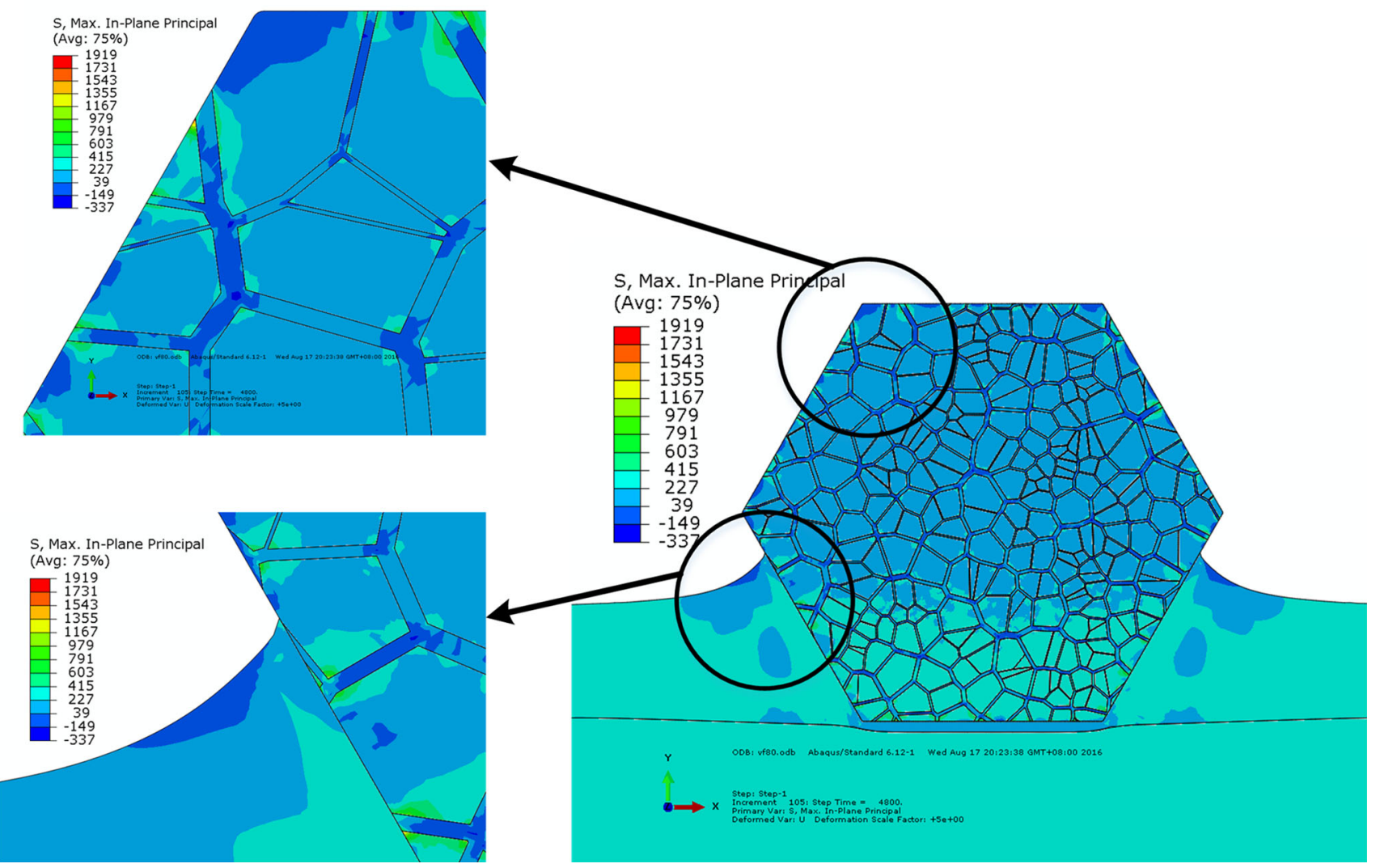

Fig. 9 Typical contour maps of residual stress distribution in brazed PCBN grains

experiments. For instance, when the brazing temperature is $900{ }^{\circ} \mathrm{C}$, the Gibbs free energies in formulas (2) and (3) are -464.8 and $-1178.7 \mathrm{~kJ} / \mathrm{mol}$, respectively [31], which indicates that the reactions may occur spontaneously.

The brazing resultant layer around the grain surface provides a chemical bridge to realize a strong bonding between $\mathrm{Ag}-\mathrm{Cu}-\mathrm{Ti}$ filler alloy and PCBN grain. As well known, the Ti-N and Ti-B resultants are brittle phases. For this reason, if the Ti-N and Ti-B resultant layer at the interface is rather thick, some cracks may take place at the brazing interface when the grains are impacted mechanically in the grinding process [32-35], resulting in grain fracture. Through the observation of brazing resultant layer, it is found that the thickness of resultant layer is appropriate when the scanning speed is $0.5 \mathrm{~mm} / \mathrm{s}$ in the current work. In comparison with a thicker resultant layer obtained in the vacuum furnace brazing [3] (reached 4-5 $\mu \mathrm{m}$ when the brazing temperature was $920^{\circ} \mathrm{C}$ and holding time was $8 \mathrm{~min}$ ), the induction brazing technique enabled a chemical combination between PCBN grains and $\mathrm{Ag}-\mathrm{Cu}-\mathrm{Ti}$ filler alloy in a shorter period of brazing time with a resultant layer of less than $1 \mu \mathrm{m}$ in thickness. This is also favorable to improve the shock resistance capability of the grain/filler joining interface in the grinding process.

\subsection{Brazing-Induced Residual Stress in PCBN Grains}

The brazing-induced residual stress, which is produced due to the mismatch of thermal expansion coefficient during the heating and cooling process, has an important influence on the mechanical strength of the PCBN grains. In order to discuss the brazing-induced residual stress, a two-dimensional (2D) model of the brazed PCBN grains was established based on finite element method (FEM) [36, 37]. The Voronoi tessellation technique was applied to construct the microstructure of PCBN grains [38-40]. The PCBN grain shape is regular hexagon with a side length of $200 \mu \mathrm{m}$. A square of the AISI 1045 steel substrate with the height of $5 \mathrm{~mm}$ and width of $2 \mathrm{~mm}$ was built. The size of microcrystalline CBN particles inside PCBN grain is around $20 \mu \mathrm{m}$. The distance from the highest interface between the PCBN grain and the $\mathrm{Ag}-\mathrm{Cu}-\mathrm{Ti}$ bonding alloy to the bottom of the grain is about $40 \%$ of the grain diameter. Particularly, the volume fraction $v_{\mathrm{f}}$, which would affect the residual stress distribution within the grain, has been put forward to evaluate the percent of the microcrystalline $\mathrm{CBN}$ particles volume inside a PCBN grain. The simulation result with the volume fraction $v_{\mathrm{f}}$ of $80 \%$ is displayed in Fig. 9. It is found that the distribution of brazing-induced stress is random, 
(a)

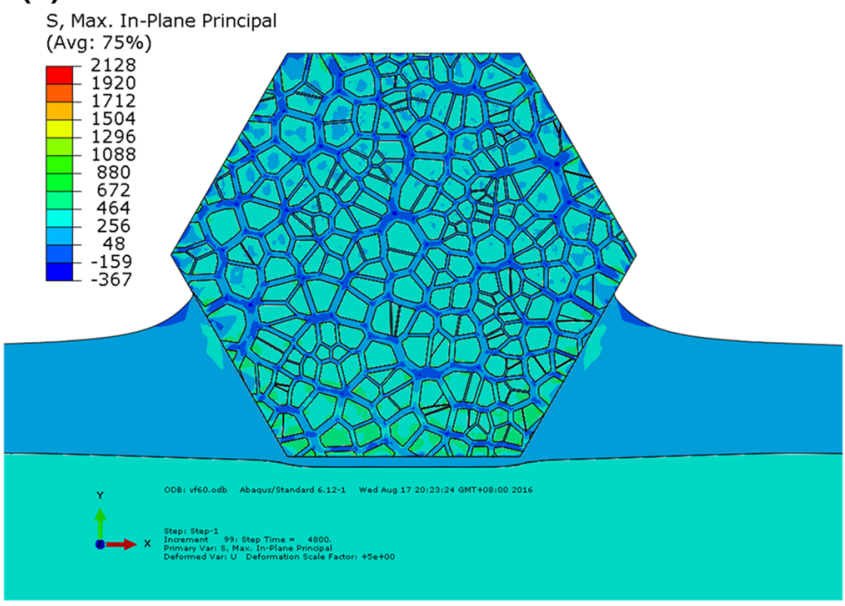

(c)

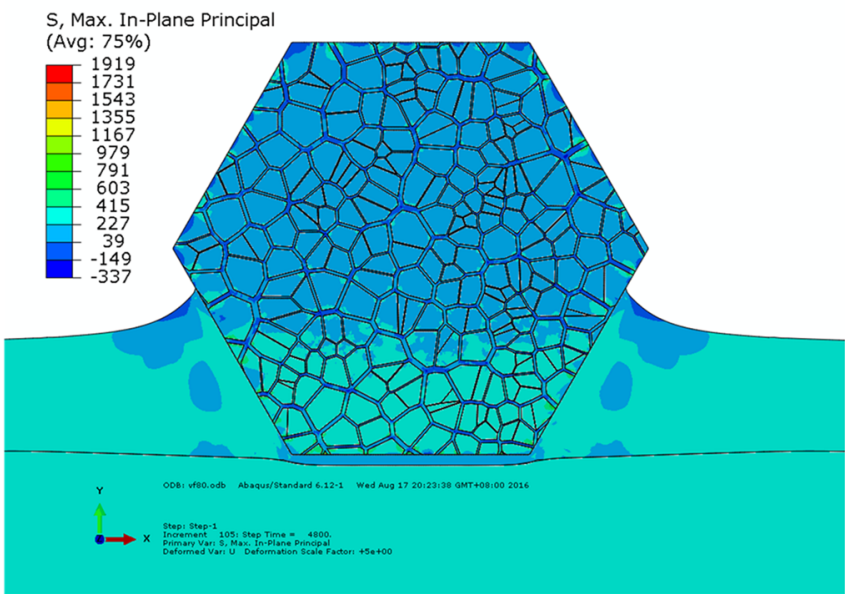

(b)

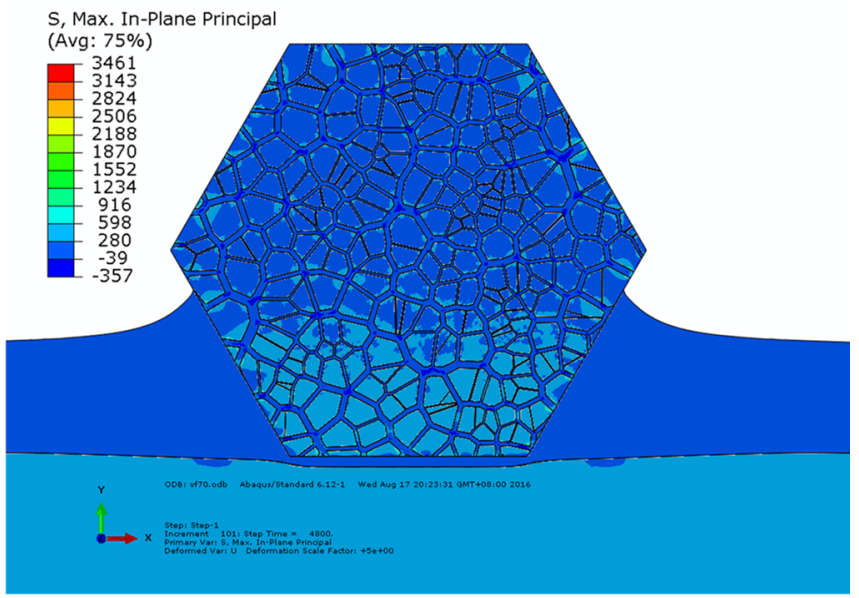

(d)

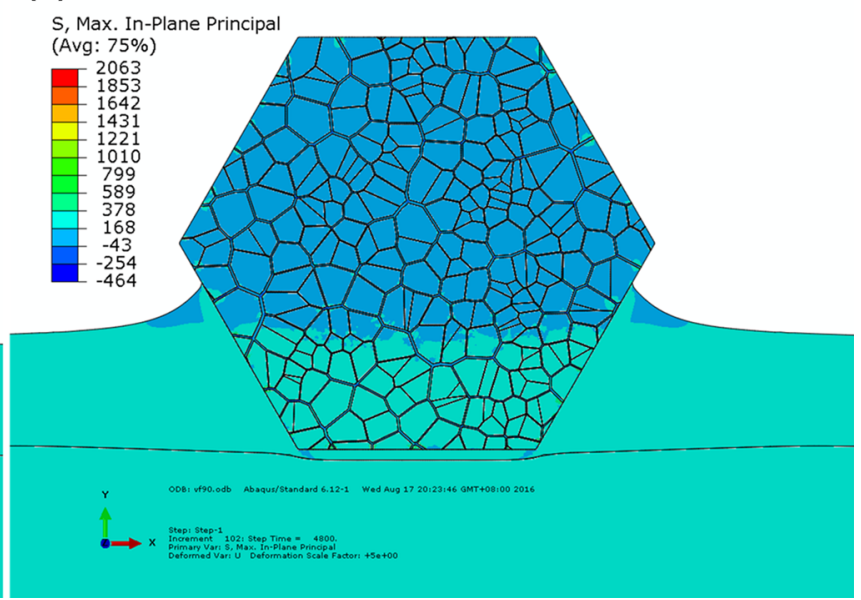

Fig. 10 Contour maps of residual stress distribution in PCBN grains with different volume fractions: a $v_{\mathrm{f}}=60 \%$, b $v_{\mathrm{f}}=70 \%$, c $v_{\mathrm{f}}=80 \%$, d $v_{\mathrm{f}}=90 \%$

and the largest tensile stress is around $1900 \mathrm{MPa}$, while the largest compressive residual stress is around $-300 \mathrm{MPa}$, which is caused due to the thermal expansion coefficient mismatch around the area of the interface among the microcrystalline CBN particles, Ag-Cu-Ti filler alloy and the AlN binder. Moreover, the residual tensile stress larger than $1700 \mathrm{MPa}$ still exists on the grain top left, which indicates that the influence of the AlN material property is greater than that of the $\mathrm{Ag}-\mathrm{Cu}-\mathrm{Ti}$ filler alloy. Figure 10 demonstrates the effect of the volume fraction $v_{\mathrm{f}}$ on the stress distribution. The simulated largest tensile stress could reach 2128, 3461, 1919 and $2063 \mathrm{MPa}$ with the volume fraction $v_{\mathrm{f}}$ range from $60 \%$ to $90 \%$, respectively. The tensile stress in a brazed PCBN grain with the volume fraction $v_{\mathrm{f}}$ of $80 \%$ is the least. In order to reduce the grain fracture during the grinding process, the largest tensile stress should be decreased [41, 42]. Therefore, the volume fraction $v_{\mathrm{f}}$ of
$80 \%$ is selected. In addition, the PCBN grain is a typical brittle material, and it is easy to fracture under large tensile stress. The large tensile stress would affect the fracture strength of the grain. In the further work, how to control the residual tensile stress in brazed PCBN grains will still be an important issue.

\section{Conclusions}

1. The brazing reaction with the resultants of $\mathrm{TiN}, \mathrm{TiB}_{2}$ and $\mathrm{TiAl}_{3}$ happened at the joining interface between $\mathrm{PCBN}$ grain and $\mathrm{Ag}-\mathrm{Cu}-\mathrm{Ti}$.

2. The optimum heating parameters, such as current magnitudes of $24 \mathrm{~A}$ and scanning speeds of $0.5 \mathrm{~mm} / \mathrm{s}$, were determined in the present induction brazing operation; at this time, the maximum heating 
temperature is $965^{\circ} \mathrm{C}$, and the highest compressive strength of brazed PCBN grains is achieved.

3. The tensile residual stress produced during the brazing process is much large, which should be controlled carefully.

Acknowledgements This work is financially supported by the National Natural Science Foundation of China (Nos. 51235004 and 51375235), the Fundamental Research Funds for the Central Universities (No. NE2014103) and the Funding for Outstanding Doctoral Dissertation in NUAA (No. BCXJ16-06).

\section{References}

[1] A. McKie, J. Winzer, I. Sigalas, M. Herrmann, L. Weiler, J. RÖdel, N. Can, Ceram. Int. 37, 8 (2011)

[2] Sunarto, Y. Ichida, Precis. Eng. 25, 283 (2001)

[3] W.F. Ding, J.H. Xu, Z.Z. Chen, Q. Miao, C.Y. Yang, Mater. Sci. Eng. A 559, 634 (2013)

[4] C. Mao, Y.H. Ren, H.Y. Gan, M.J. Zhang, J. Zhang, K. Tang, Int. J. Adv. Manuf. Technol. 76, 2049 (2015)

[5] W.F. Ding, J.H. Xu, Z.Z. Chen, H.H. Su, Y.C. Fu, Int. J. Adv. Manuf. Technol. 52, 976 (2011)

[6] Y. Ichida, Diam. Relat. Mater. 17, 1795 (2008)

[7] Y. Ichida, M. Fujimoto, Y. Inoue, K. Matsui, Development of a high performance vitrified grinding wheel using ultrafine-crystalline $\mathrm{cBN}$ abrasive grains. Paper presented at 5th International Conference on Leading Edge Manufacturing in 21st Century, Osaka university, Osaka, Japan, 2-4 Dec 2009

[8] J.X. Lu, W.X. Yang, S.K. Wu, X.D. Zhao, R.S. Xiao, Acta Metall. Sin. (Engl. Lett.) 27, 676 (2014)

[9] M.R. Johari, A.M. Hadian, Ceram. Int. 40, 8524 (2014)

[10] C. Dharmendra, K.P. Rao, J. Wilden, S. Reich, Mater. Sci. Eng. A 528, 1503 (2011)

[11] Y. Wang, X.Q. Cai, Z.W. Yang, Q.W. Qiu, D.P. Wang, Y.C. Liu, Mater. Chem. Phys. 182, 497 (2016)

[12] N. Wang, D.P. Wang, Z.W. Yang, Y. Wang, Ceram. Int. 42, 12824 (2016)

[13] W. Xu, W.F. Ding, Y.J. Zhu, X. Huang, Y.C. Fu, Int. J. Adv. Manuf. Technol. 88, 1075 (2017)

[14] L. Ma, P.X. Qiao, W.M. Long, D.Y. He, Mater. Des. 37, 469 (2012)

[15] Q.W. Qiu, Y. Wang, Z.W. Yang, D.P. Wang, J. Eur. Ceram. Soc. 36, 2074 (2016)

[16] W. Tillmann, M. Zimpel, J. Pfeiffer, L. Wojarski, Z.W. Xu, Weld. World 59, 909 (2015)

[17] M. Rozanski, D. Majewski, K. Krasnowski, Arch. Metall. Mater. 60, 2597 (2015)

[18] D.K. Aspinwall, S.L. Soo, D.T. Curtis, A.L. Mantle, CIRP Ann. Manuf. Technol. 56, 338 (2007)
[19] J. Elanchezhian, M.P. Kumar, G. Manimaran, J. Mech. Sci. Technol. 29, 4890 (2015)

[20] X. Tong, H.H. Su, J.H. Xu, Y. Chen, Trans. China Weld. Inst. 36, 54 (2015). (in Chinese)

[21] B.J. Ma, Q. Pang, J.P. Lou, Int. J. Refract. Metals Hard Mater. 43, 29 (2014)

[22] B.J. Ma, J.P. Lou, Q. Pang, J. Mater. Eng. Perform. 23, 1510 (2014)

[23] Q.L. Li, J.H. Xu, H.H. Su, W.N. Lei, Int. J. Adv. Manuf. Technol. 80, 1180 (2015)

[24] H. Huang, X.H. Zhu, Q.K. Huang, X.Z. Hu, Eng. Fract. Mech. 52, 24 (1995)

[25] T.Y. Yu, A.F. Bastawros, A. Chandra, Experimental characterization of electroplated CBN grinding wheel wear: topology evolution and interfacial toughness. Paper presented at the ASME 2014 International Manufacturing Science and Engineering Conference, University of Michigan, Detroit, Michigan, 9-13 June 2014

[26] C.W. Ma, K. Shi, Z.S. Yu, P.Q. Xu, Acta Metall. Sin. (Engl. Lett.) 24, 212 (2011)

[27] D.Z. Duan, B. Xiao, B. Wang, P. Han, Int. J. Refract. Hard Metals 48, 432 (2015)

[28] B.T. Lee, Y.J. Yoon, K.H. Lee, Mater. Lett. 85, 76 (2012)

[29] Z.L. Yang, J.H. Ouyang, Z.G. Liu, Mater. Des. 32, 35 (2011)

[30] K. Wang, C. Cui, Q. Wang, S. Liu, C. Gu, Mater. Lett. 85, 156 (2012)

[31] C.E. Wicks, F.E. Block, Thermodynamic Properties of 65 Elements-their Oxide, Carbide, and Nitride (US Government Print Office, Washington, DC, 1963), p. 123

[32] B. Pal, A.K. Chattopadhyay, Int. J. Adv. Manuf. Technol. 48, 944 (2010)

[33] L. Yan, Y.M. Rong, F. Jiang, Z.X. Zhou, Int. J. Adv. Manuf. Technol. 55, 141 (2011)

[34] Z.Y. Zhang, F.W. Huo, X.Z. Zhang, D.M. Guo, Scr. Mater. 67, 660 (2012)

[35] X.P. Zhang, C.H. Li, Y.B. Zhang, D.Z. Jia, B.K. Li, Y.G. Wang, M. Yang, Y.L. Hou, X.W. Zhang, Int. J. Adv. Manuf. Technol. 86, 3441 (2016)

[36] Z.Y. Huang, Q. Shi, F.Q. Chen, Y.F. Shi, Acta Metall. Sin. (Engl. Lett.) 27, 421 (2014)

[37] Z.Z. Yang, D.X. Liu, X.H. Zhang, Acta Metall. Sin. (Engl. Lett.) 26, 198 (2013)

[38] H. Li, K. Li, G. Subhash, L.J. Kecskes, R.J. Dowding, Mater. Sci. Eng. A 429, 123 (2006)

[39] B. Shen, B. Song, L. Cheng, X.L. Lei, F.H. Sun, Surf. Coat. Technol. 253, 131 (2014)

[40] T. Yu, K. Yoshida, H.J. Shi, Acta Metall. Sin. (Engl. Lett.) 24, 219 (2011)

[41] X.P. Xu, X.R. Tie, H.R. Wu, Int. J. Refract. Metals Hard Mater. 25, 249 (2007)

[42] W.X. Xu, L.C. Zhang, Int. J. Mach. Tools Manuf. 80-81, 10 (2014) 